\title{
Implementasi Data Mining dalam Mengelompokkan Rumah Tangga Kumuh di Perkotaan Berdasarkan Provinsi Menggunakan Algoritma K-Means
}

\author{
Ranti Andini Margolang1, Sundari Retno Andani ${ }^{2}$, Muhammad Ridwan Lubis ${ }^{3}$ \\ STIKOM Tunas Bangsa Pematangsiantar \\ Jln. Jendral Sudirman Blok A No. 1,2,3 Pematangsiantar \\ rantiandini1605@gmail.com
}

\begin{abstract}
Slum is an area with a high population density levels in the city are generally inhabited by the poor and the unemployment rate is high, the slum also became a center of health problems because the conditions are not higenis. Slum slum household is is the home that do not have access to a source of drinking water, have no access to decent sanitation, have no access to floor area $>=7.2 \mathrm{~m}^{2} \mathrm{Per}$ capita, and do not have access to conditions the roof, floor, and walls. This study used data sourced from the Central Bureau of statistics the year 2015 - 2016. The method used is Datamining the K-Means Clustering, Clustering is a method used in datamining the how it works find and classify data that has a semblance and characteristics of data between one another with the data. Using this algorithm the data already obtained can be grouped into Clusters based on this data. This data can be entered to the local Government to recommend to the Government so that the Government can handle the Spreader area development assistance to areas of slum households.
\end{abstract}

Keywords: Slum Household, Data Mining, K-Means.

Abstrak - Kawasan kumuh merupakan sebuah kawasan dengan tingkat kepadatan populasi tinggi disebuah kota yang umumnya dihuni oleh masyarakat miskin dan tingkat pengangguran yang tinggi, kawasan kumuh juga menjadi pusat masalah kesehatan karna kondisinya yang tidak higenis. Rumah tangga kumuh adalah rumah yang tidak memiliki akses terhadap sumber air minum, tidak memiliki akses terhadap sanitasi layak, tidak memiliki akses terhadap luas lantai $>=7,2 \mathrm{~m}^{2}$ per kapita, dan tidak memiliki akses terhadap kondisi atap, lantai, dan dinding yang layak. Penelitian ini data yang digunakan bersumber dari Badan Pusat Statistik Tahun 2015 - 2016. Metode yang digunakan adalah Data mining K-Means Clustering. Dengan menggunakan metode ini data-data yang telah diperoleh dapat dikelompokkan ke dalam beberapa cluster, dimana penerapan proses $K$ Means Clustering menggunakan tools RapidMiner. Data diolah dibagi dalam 3 cluster yaitu: cluster tinggi (C1), cluster sedang (C2) dan cluster rendah (C3). Proses iterasi penelitian ini terjadi sebanyak 4 kali iterasi sehingga diperoleh penilaian dalam mengelompokkan rumah tangga kumuh berdasarkan provinsi. Hasil yang diperoleh bahwa terdapat 2 provinsi dengan cluster tertinggi (C1), 16 provinsi dengan cluster sedang (C2), dan 16 provinsi dengan cluster terendah (C3). Data ini dapat menjadi masukkan kepada pemerintah setempat untuk merekomendasikan kepada pemerintah agar pemerintah dapat menangani Penyebarluasan bantuan pembangunan untuk daerah rumah tangga kumuh.

Kata Kunci: Rumah Tangga Kumuh, Data Mining, K-Means. 


\section{PENDAHULUAN}

Rumah Tangga Kumuh Merupakan Rumah yang tidak memiliki akses terhadap sumber air minum, tidak memiliki akses terhadap sanitasi layak, tidak memiliki akses terhadap luas lantai $>=7,2 \mathrm{~m}^{2}$ Per kapita, dan tidak memiliki akses terhadap kondisi atap, lantai, dan dinding yang layak. Melihat kondisi hunian kumuh di Indonesia, pemerintah berusaha mengurangi keberadaannya melalui berbagai program. Sejak tahun 2004, pemerintah pusat dalam hal ini Kementerian Perumahan Rakyat telah menggulirkan beberapa program untuk peningkatan kualitas lingkungan perumahan terutama bagi Masyarakat Berpenghasilan Rendah (MBR). Melihat kondisi rumah yang sangat memprihatinkan sebagaimana dijelaskan diatas, memang sudah sepantasnya kualitas lingkungan dan rumahrumah tersebut mendapat bantuan untuk diperbaiki. Namun pemerintah melalui program PLP2K-BK ini kesulitan melaksanakan bantuan penataan lingkungan khususnya yang berkaitan dengan perbaikan rumah-rumah kumuh yang ada tersebut karena status rumah dan tanah yang berbeda pemilik. Sesuai peraturan, pemerintah hanya dapat memberikan bantuan perbaikan pada rumah yang alas tanahnya berstatus milik sedangkan kondisi yang ada di lokasi tersebut adalah didalam petak yang sama namun pemilik rumah dan pemilik tanah berbeda. Kondisi ini jelas menutup kemungkinan bantuan pemerintah untuk perbaikan rumah-rumah kumuh karena kepemilikan rumah dan tanah harus pada pihak yang sama[1] .

Berdasarkan penelitian terdahulu yang dilakukan oleh Tinus Septioko Mahasiswa Program Studi Matematika FSM UKSW yang berjudul "Aplikasi K-Means untuk pengelompokkan Rumah Tangga di Salatiga berdasarkan data susenas 2011" Dari penelitian tesebut dapat disimpulkan bahwa hasil cluster akhir yang diperoleh dengan program SPSS[2].

\section{METODOLOGI PENELITIAN}

\subsection{Analisa Data}

Analisis data dilakukan setelah adanya pengumpulan data. Dalam melakukan penelitian ini penulis menggunakan analisis data sekunder. Data Sekunder adalah sumber data penelitian yang diperoleh melalui media perantara atau secara tidak langsung yang berupa buku, catatan, bukti yang telah ada, atau arsip baik yang telah dipublikasi atau tidak dipublikasi secara umum. Data yang diperoleh dari penelitian ini adalah melalui situs resmi https://www.bps.go.id_atau BPS (Badan Pusat Statistik) yakni persentase rumah tangga kumuh perkotaan pada tahun 2015 sampai 2016. Data ini akan diolah dengan melakukan clustering persentase rumah tangga kumuh diperkotaan menjadi 3 cluster yaitu, cluster tertinggi, cluster sedang, dan cluster terendah.

\subsection{Data Mining}

Data mining merupakan proses menemukan korelasi baru yang bermanfaat, pola dan trend dengan menambang sejumlah repository data dalam jumlah besar, menggunakan teknologi pengenalan pola seperti statistik dan teknik matematika [3]. 


\subsection{Algoritma K-Means}

K-Means merupakan Algoritma pengelompokan iteratif yang melakukan partisi set data ke dalam sejumlah $\mathrm{K}$ cluster yang sudah ditetapkan diawal. Algoritma K-Means sederhana untuk diimplementasikan dan dijalankan, relative cepat, mudah beradaptasi, umum penggunaannya dalam praktek [4]-[7]. Secara historis, K-Means menjadi salah satu algoritma yang paling penting dalam bidang data miningb [8]. Berikut ini adalah langkah-langkah dalam algoritma K-means [9].

1. Tentukan jumlah cluster $(\mathrm{k})$ pada data set

2. Tentukan nilai pusat (centroid)

Penentuan nilai centroid pada tahap awal dilakukan secara random, sedangkan pada tahap iterasi digunakan rumus seperti pada persamaan (1) berikut ini :

$\mathrm{V}_{\mathrm{ij}}=\frac{1}{N i} \sum_{k=0}^{N i} \mathrm{Xkj}$

Keterangan :

$\mathrm{V}_{\mathrm{ij}} \quad=$ centroid rata-rata cluster ke-I untuk variabel ke-j

$\mathrm{N}_{\mathrm{i}} \quad$ = Jumlah anggota cluster ke-i

i, $k \quad=$ indeks dari cluster

$\mathrm{j}=$ indeks dari variabel

Xkj = nilai data ke-k variabel ke-j untuk cluster tersebut

3. Pada masing-masing record, hitung jarak terdekat dengan centroid. Jarak centroid yang digunakan adalah Euclidean Distance, dengan rumus seperti pada persamaan (2) :

$D e=\sqrt{(x i-s i)^{2}+(y i-t i)^{2}}$

Keterangan :

De $\quad=$ Eulidean Distance

$\mathrm{i} \quad=$ Banyaknya objek $^{2}$

$(\mathrm{x}, \mathrm{y}) \quad=$ Koordinat objek

$(\mathrm{s}, \mathrm{t}) \quad=$ Koordinat centroid

4. Kelompokkan objek berdasarkan jarak ke centroid terdekat

5. Ulangi langkah ke-2, lakukan iterasi hingga centroid bernilai optimal

\section{HASIL DAN PEMBAHASAN}

\subsection{Analisa Algoritma K-Means}

a. Sumber Data

Menentukan jumlah data yang akan di cluster, dimana sampel data rumah tangga kumuh perkotaan yang akan digunakan dalam proses clustering adalah data jumlah rumah tangga kumuh yang terdapat pada Badan Pusat Statistik pada tahun 2015-2016 dengan jumlah data sebanyak 34 Provinsi. Berikut adalah tabel 1 data rumah tangga kumuh perkotaan.

Tabel 1. Data Rumah Tangga Kumuh 


\begin{tabular}{|c|c|c|c|c|}
\hline \multirow[t]{2}{*}{ No } & \multirow[t]{2}{*}{ Provinsi } & \multicolumn{2}{|c|}{ Tahun } & \multirow{2}{*}{$\begin{array}{c}\text { Nilai Rata-Rata Tahun } \\
2015 \text { / } 2016\end{array}$} \\
\hline & & 2015 & 2016 & \\
\hline 1 & Aceh & 9,33 & 8,45 & 8,89 \\
\hline 2 & Sumatera Utara & 9,82 & 9,36 & 9,59 \\
\hline 3 & Sumatera Barat & 12,58 & 13,02 & 12,8 \\
\hline 4 & Riau & 8,89 & 5,63 & 7,26 \\
\hline 5 & Jambi & 6,48 & 8,73 & 7,605 \\
\hline 6 & Sumatera Selatan & 15,01 & 16,13 & 15,57 \\
\hline 7 & Bengkulu & 11,41 & 12,44 & 11,925 \\
\hline 8 & Lampung & 6,88 & 4,82 & 5,85 \\
\hline 9 & Kep, Bangka Belitung & 5,85 & 5,42 & 5,635 \\
\hline 10 & Kep, Riau & 4,23 & 3,83 & 4,03 \\
\hline 11 & Dki Jakarta & 13,25 & 11,02 & 12,135 \\
\hline 12 & Jawa Barat & 14,09 & 11,81 & 12,95 \\
\hline 13 & Jawa Tengah & 4,49 & 3,7 & 4,095 \\
\hline 14 & Di Yogyakarta & 4,18 & 3,32 & 3,75 \\
\hline 15 & Jawa Timur & 4,78 & 4,57 & 4,675 \\
\hline 16 & Banten & 8,73 & 7,16 & 7,945 \\
\hline 17 & Bali & 4,73 & 2,97 & 3,85 \\
\hline 18 & Nusa Tenggara Barat & 12,5 & 11,35 & 11,925 \\
\hline 19 & Nusa Tenggara Timur & 28,13 & 27,09 & 27,61 \\
\hline 20 & Kalimantan Barat & 7,89 & 6,07 & 6,98 \\
\hline 21 & Kalimantan Tengah & 12,47 & 9,57 & 11,02 \\
\hline 22 & Kalimantan Selatan & 11,34 & 9,29 & 10,315 \\
\hline 23 & Kalimantan Timur & 7,4 & 6,69 & 7,045 \\
\hline 24 & Kalimantan Utara & 16,15 & 12,61 & 14,38 \\
\hline 25 & Sulawesi Utara & 19,15 & 11,27 & 15,21 \\
\hline 26 & Sulawesi Tengah & 14,52 & 14,69 & 14,605 \\
\hline 27 & Sulawesi Selatan & 7,49 & 5,56 & 6,525 \\
\hline 28 & Sulawesi Tenggara & 11,26 & 13,14 & 12,2 \\
\hline 29 & Gorontalo & 11,54 & 19,55 & 15,545 \\
\hline 30 & Sulawesi Barat & 12,44 & 11,05 & 11,745 \\
\hline 31 & Maluku & 19,22 & 16,72 & 17,97 \\
\hline 32 & Maluku Utara & 5,22 & 7,56 & 6,39 \\
\hline 33 & Papua Barat & 19,31 & 25,7 & 22,505 \\
\hline 34 & Papua & 20,85 & 14,44 & 17,645 \\
\hline
\end{tabular}

\section{b. Centroid Data}

Menentukan nilai centroid (pusat cluster) awal yang telah ditentukan secara random berdasarkan nilai variabel data yang di cluster sebanyak $\mathrm{k}$ yang ditentukan sebelumnya. Adapun cluster tertinggi diproleh dari nilai tertinggi pada tabel 1, cluster sedang diambil dari nilai rata-rata pada tabel 1, dan cluster terendah diambil dari nilai terkecil pada tabel 1 . berikut adalah tabel penentuan centroid awal tiap cluster.

Tabel 2. Penentuan Pusat Awal cluster

\begin{tabular}{|l|c|}
\hline Menentukan Nilai Cluster & 2015 / 2016 \\
\hline Cluster Tertinggi & 27,610 \\
\hline Cluster Sedang & 10,829 \\
\hline Cluster Terendah & 3,750 \\
\hline
\end{tabular}




\section{c. Clustering Data}

Proses clustering dengan menggunakan nilai centroid awal yang terdapat pada tabel 2, akan memperoleh hasil pengelompokkan pada iterasi 4 yang dapat dilihat pada tabel dibawah ini

Tabel 3. Posisi Data Dengan Tiap Cluster Pada Iterasi Ke-4

\begin{tabular}{|c|c|c|c|c|}
\hline \multirow[t]{2}{*}{ No } & \multirow[t]{2}{*}{ Provinsi } & \multicolumn{3}{|c|}{ Cluster } \\
\hline & & C 1 & C 2 & C 3 \\
\hline 1 & Aceh & & & 1 \\
\hline 2 & Sumatera Utara & & & 1 \\
\hline 3 & Sumatera Barat & & 1 & \\
\hline 4 & Riau & & & 1 \\
\hline 5 & Jambi & & & 1 \\
\hline 6 & Sumatera Selatan & & 1 & \\
\hline 7 & Bengkulu & & 1 & \\
\hline 8 & Lampung & & & 1 \\
\hline 9 & Kep, Bangka Belitung & & & 1 \\
\hline 10 & Kep, Riau & & & 1 \\
\hline 11 & Dki Jakarta & & 1 & \\
\hline 12 & Jawa Barat & & 1 & \\
\hline 13 & Jawa Tengah & & & 1 \\
\hline 14 & Di Yogyakarta & & & 1 \\
\hline 15 & Jawa Timur & & & 1 \\
\hline 16 & Banten & & & 1 \\
\hline 17 & Bali & & & 1 \\
\hline 18 & Nusa Tenggara Barat & & 1 & \\
\hline 19 & Nusa Tenggara Timur & 1 & & \\
\hline 20 & Kalimantan Barat & & & 1 \\
\hline 21 & Kalimantan Tengah & & 1 & \\
\hline 22 & Kalimantan Selatan & & 1 & \\
\hline 23 & Kalimantan Timur & & & 1 \\
\hline 24 & Kalimantan Utara & & 1 & \\
\hline 25 & Sulawesi Utara & & 1 & \\
\hline 26 & Sulawesi Tengah & & 1 & \\
\hline 27 & Sulawesi Selatan & & & 1 \\
\hline 28 & Sulawesi Tenggara & & 1 & \\
\hline 29 & Gorontalo & & 1 & \\
\hline 30 & Sulawesi Barat & & 1 & \\
\hline 31 & Maluku & & 1 & \\
\hline 32 & Maluku Utara & & & 1 \\
\hline 33 & Papua Barat & 1 & & \\
\hline 34 & Papua & & 1 & \\
\hline
\end{tabular}

Berdasarkan tabel 3 diperoleh pengelompokkan Cluster Pertama dengan jumlah data rumah tangga kumuh sebanyak 2 provinsi yaitu Nusa Tenggara Timur dan Papua Barat. Cluster Kedua jumlah data rumah tangga Kumuh sebanyak 16 Provinsi yaitu, Sumatera Barat, Sumatera Selatan, Bengkulu, Dki Jakarta, Jawa Barat, Nusa Tenggara Barat, Kalimantan Tengah, Kalimantan Selatan, Kalimantan Utara, Sulawesi Utara, Sulawesi Tengah, Sulawesi Tenggara, Gorontalo, Sulawesi Barat, Maluku, dan Papua. Cluster Ketiga jumlah data rumah tangga kumuh 
sebanyak 16 Provinsi yaitu Aceh, Sumatera Utara, Riau,Jambi, Lampung, Kep Bangka Belitung, Kep Riau, Jawa Tengah, DI Yogyakarta, Jawa Timur, Banten, Bali, Kalimantan Barat, Kalimantan Timur, Sulawesi Selatan, dan Maluku Utara.

\subsection{Hasil}

Hasil penelitian yang dilakukan sebelumnya, data yang digunakan dalam penelitian ini adalah data persentase rumah tangga kumuh perkotaan menurut provinsi. Aplikasi yang digunakan yaitu rapidminer 5.0. Data yang telah didapatkan ditransformasikan ke format data excel 2013 dan diolah menggunakan algoritma K-Means dalam menentukan cluster tinggi, cluster sedang, dan cluster rendah, untuk mengetahui sejauh mana tinggi rumah tangga kumuh diperkotaan. Berikut ini adalah provinsi provinsi mana saja yang termasuk dalam cluster 1, 2 atau 3 terdapat pada gambar berikut

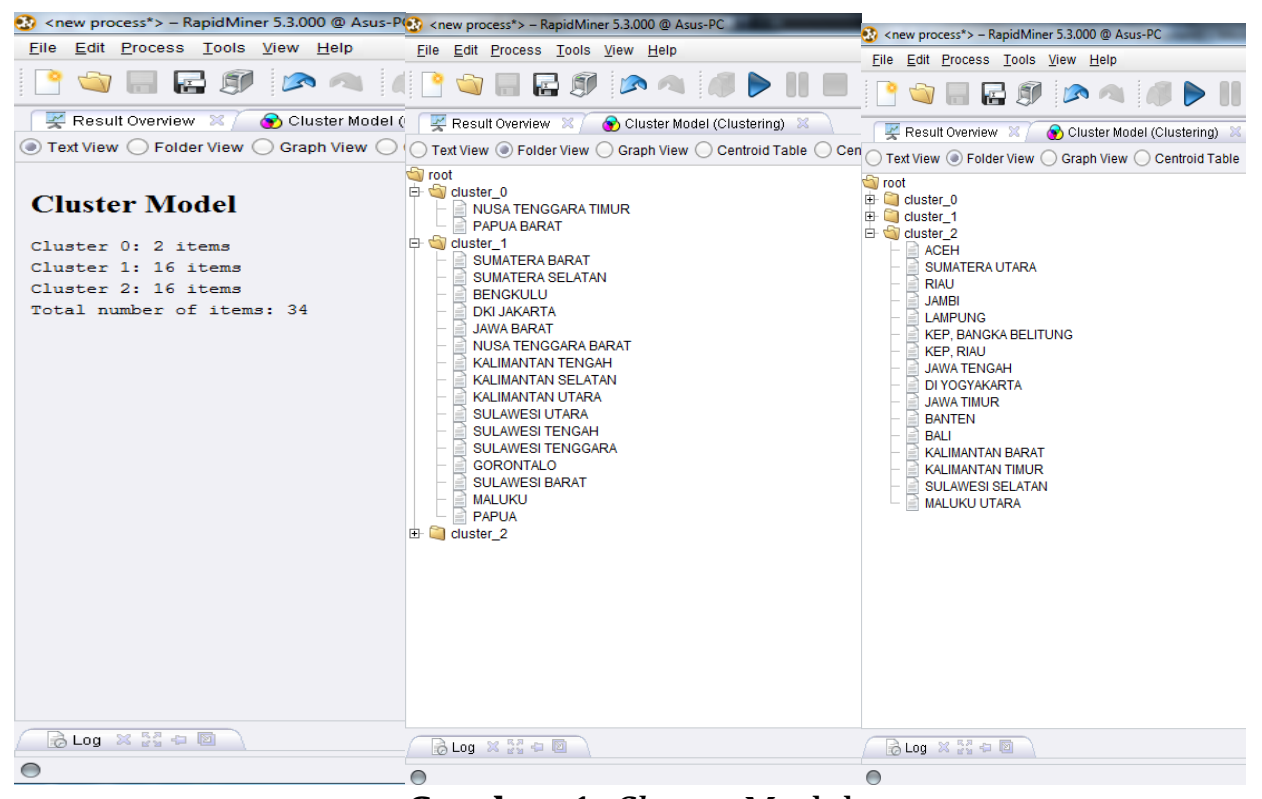

Gambar 1. Cluster Model

\subsection{Pembahasan}

Berdasarkan penjelasan diatas mengenai penggunaan serta hasil yang telah ditampilkan, keterkaitan dari hasil yang diproleh antara perhitungan algoritma dengan hasil pengujian pada tool rapidminer.

Tabel 4. Perbandingan Hasil Akhir K-Means

\begin{tabular}{|l|l|l|}
\hline \multicolumn{1}{|c|}{ Provinsi } & Perhitungan Algoritma K-Means & Pengujian Dengan Rapidminer \\
\hline Aceh & cluster_3 & cluster_2 \\
\hline Sumatera Utara & cluster_3 & cluster_2 \\
\hline Sumatera Barat & cluster_2 & cluster_1 \\
\hline Riau & cluster_3 & cluster_2 \\
\hline Jambi & cluster_3 & cluster_2 \\
\hline Sumatera Selatan & cluster_2 & cluster_1 \\
\hline Bengkulu & cluster_2 & cluster_1 \\
\hline
\end{tabular}




\begin{tabular}{|c|c|c|}
\hline Provinsi & Perhitungan Algoritma K-Means & Pengujian Dengan Rapidminer \\
\hline Lampung & cluster_3 & cluster_2 \\
\hline Kep. Bangka Belitung & cluster_3 & cluster_2 \\
\hline Kep. Riau & cluster_3 & cluster_2 \\
\hline Dki Jakarta & cluster_2 & cluster_1 \\
\hline Jawa Barat & cluster_2 & cluster_1 \\
\hline Jawa Tengah & cluster_3 & cluster_2 \\
\hline Di Yogyakarta & cluster_3 & cluster_2 \\
\hline Jawa Timur & cluster_3 & cluster_2 \\
\hline Banten & cluster_3 & cluster_2 \\
\hline Bali & cluster_3 & cluster_2 \\
\hline Nusa Tenggara Barat & cluster_2 & cluster_1 \\
\hline Nusa Tenggara Timur & cluster_1 & cluster_0 \\
\hline Kalimantan Barat & cluster_3 & cluster_2 \\
\hline Kalimantan Tengah & cluster_2 & cluster_1 \\
\hline Kalimantan Selatan & cluster_2 & cluster_1 \\
\hline Kalimantan Timur & cluster_3 & cluster_2 \\
\hline Kalimantan Utara & cluster_2 & cluster_1 \\
\hline Sulawesi Utara & cluster_2 & cluster_1 \\
\hline Sulawesi Tengah & cluster_2 & cluster_1 \\
\hline Sulawesi Selatan & cluster_3 & cluster_2 \\
\hline Sulawesi Tenggara & cluster_2 & cluster_1 \\
\hline Gorontalo & cluster_2 & cluster_1 \\
\hline Sulawesi Barat & cluster_2 & cluster_1 \\
\hline Maluku & cluster_2 & cluster_1 \\
\hline Maluku Utara & cluster_3 & cluster_2 \\
\hline Papua Barat & cluster_1 & cluster_0 \\
\hline Papua & cluster_2 & cluster_1 \\
\hline \multirow[t]{3}{*}{ Hasil } & cluster_1 & 2 \\
\hline & cluster_2 & 16 \\
\hline & cluster_3 & 16 \\
\hline
\end{tabular}

\section{KESIMPULAN}

Dari hasil penelitian yang telah dilakukan, maka penulis dapat menarik beberapa kesimpulan, diantaranya sebagai berikut:

1. Mengelompokkan rumah tangga kumuh yang ada diprovinsi indonesia berhasil diterapkan menggunakan Algoritma K-Means Clustering.

2. Pengujian yang dilakukan dalam penelitian ini, iterasi clustering pada data rumah tangga kumuh terjadi sebanyak 4 kali iterasi,

3. Data tersebut diolah menggunakan Rapidminer untuk ditentukan nilai centroid dalam 3 cluster yaitu cluster tinggi (C1), cluster tinggkat sedang (C2), dan cluster tinggat rendah (C3).

\section{DAFTAR PUSTAKA}

[1] N. Noegroho, "PENATAAN HUNIAN KUMUH PERKOTAAN DI ATAS TANAH ULAYAT: STUDI KASUS PADA KOTA PAYAKUMBUH, SUMATERA BARAT Pemerintah dan Program Penataan Hunian Kumuh," vol. 2, no. 2, pp. 618-626, 2011.

[2] T. Septioko et al., "APLIKASI K-MEANS UNTUK PENGELOMPOKAN RUMAH TANGGA APLIKASI K-MEANS UNTUK PENGELOMPOKAN RUMAH TANGGA DI SALATIGA BERDASARKAN DATA SUSENAS 2011," 2011. 
[3] F. Kiki and A. P. Windarto, "DATA MINING : PENERAPAN RAPIDMINER DENGAN K-MEANS CLUSTER PADA DAERAH TERJANGKIT DEMAM BERDARAH DENGUE ( DBD ) BERDASARKAN PROVINSI," vol. 3, no. 2, pp. 173-178, 2018.

[4] I. Parlina, A. P. Windarto, A. Wanto, and M. R. Lubis, "Memanfaatkan Algoritma K-Means dalam Menentukan Pegawai yang Layak Mengikuti Asessment Center untuk Clustering Program SDP," CESS (Journal of Computer Engineering System and Science), vol. 3, no. 1, pp. 87-93, 2018.

[5] S. Sudirman, A. P. Windarto, and A. Wanto, "Data Mining Tools | RapidMiner : K-Means Method on Clustering of Rice Crops by Province as Efforts to Stabilize Food Crops In Indonesia," IOP Conference Series: Materials Science and Engineering, vol. 420, no. 12089, pp. 1-8, 2018.

[6] R. W. Sari, A. Wanto, and A. P. Windarto, "Implementasi Rapidminer dengan Metode K-Means (Study Kasus: Imunisasi Campak pada Balita Berdasarkan Provinsi)," KOMIK (Konferensi Nasional Teknologi Informasi dan Komputer), vol. 2, no. 1, pp. 224-230, 2018.

[7] M. G. Sadewo, A. P. Windarto, and A. Wanto, "Penerapan Algoritma Clustering dalam Mengelompokkan Banyaknya Desa/Kelurahan Menurut Upaya Antisipasi/ Mitigasi Bencana Alam Menurut Provinsi dengan K-Means," KOMIK (Konferensi Nasional Teknologi Informasi dan Komputer), vol. 2, no. 1, pp. 311-319, 2018.

[8] H. Sulastri and A. I. Gufroni, "Jurnal Teknologi dan Sistem Informasi PENERAPAN DATA MINING DALAM PENGELOMPOKAN PENDERITA,” vol. 2, pp. 299-305, 2017.

[9] E. G. Sihombing, "Klasifikasi Data Mining Pada Rumah Tangga Menurut Provinsi Dan Status Kepemilikan Rumah Kontrak / Sewa Menggunakan K-Means Clustering Method,” vol. 2, no. 2, pp. 74-82, 2017. 